\title{
Lymphocytic vacuolization in sialic acid storage disease
}

\author{
Barıs Kuskonmaz, ${ }^{1}$ * Sule Unal, ${ }^{1}$ Emine Cördükcü, ${ }^{2}$ Halil Aydin, ${ }^{3}$ Turgay Coskun, ${ }^{3}$ \\ Aytemiz Gurgey, ${ }^{1}$ and Fatma Gumruk ${ }^{1}$
}

An 8-month-old boy was referred to our hospital with the complaints of fever, diarrhea, vomiting, and weight loss of three months' duration. The parents stated that he had no inclination to sit and was "weaker" than his siblings. The child, the product of consanguineous (1st cousins) parents, was born premature at the 36th week of gestation with a birth weight of $2,920 \mathrm{~g}$ as the second child of the family. Nonimmune hydrops fetalis and oligohydromnios were detected during the prenatal period. His older sibling, also born premature, had died with similar complaints during the infancy period.

On admission, physical examination revealed body weight at 4,800 g (below 3rd percentile), length $64 \mathrm{~cm}$ (3rd percentile), and head circumference $42 \mathrm{~cm}$ (below $3 \mathrm{rd}$ percentile). The child appeared pale and exhibited coarse facial appearance with long philtrum, depressed nasal bridge, and micrognathia, oral moniliasis. The liver was palpable $4 \mathrm{~cm}$ below the right costal margin. Traube's space was dull on percussion and he had ascites, hydrocele, edema, and scrotal hernia.

Complete blood count revealed $\mathrm{Hb} 8.3 \mathrm{~g} / \mathrm{dL}$, WBC 13.7 $\times 10^{9} / \mathrm{L}$, platelet $221 \times 10^{9} / \mathrm{L}, \mathrm{MCHC} 72.9 \mathrm{fL}$, RDW 19.6. Peripheral blood smear showed vacuolization of lymphocytes (20\% of the lymphocytes), but no vacuolization was prominent in nonlymphoid cells (see Image 1). Urinary free sialic acid excretion was found to be increased $(108 \mu \mathrm{mol} /$ $\mathrm{mmol}$ creatinine, reference range of age-matched controls $30.4 \mu \mathrm{mol} / \mathrm{mmol}-38 \mu \mathrm{mol} / \mathrm{mmol}$ ), and thus diagnosis of Sialic Acid Storage Disease was made.

Free sialic acid disorders are rare autosomal recessive diseases characterized by the intracellular accumulation of $\mathrm{N}$-acetylneuraminic acid (sialic acid). Lysosomal storage of free sialic acid results from a genetic defect in transport of this charged sugar out of the lysosomes. There are other forms of the disease, including the milder autosomal recessive disorders of Salla disease and infantile free sialic acid storage disease (ISSD), and some intermediate forms. The milder type i.e., Salla disease is common in Finland, and newborns develop intellectual impairment gradually. In the more severe allelic variant, i.e., infantile free sialic acid

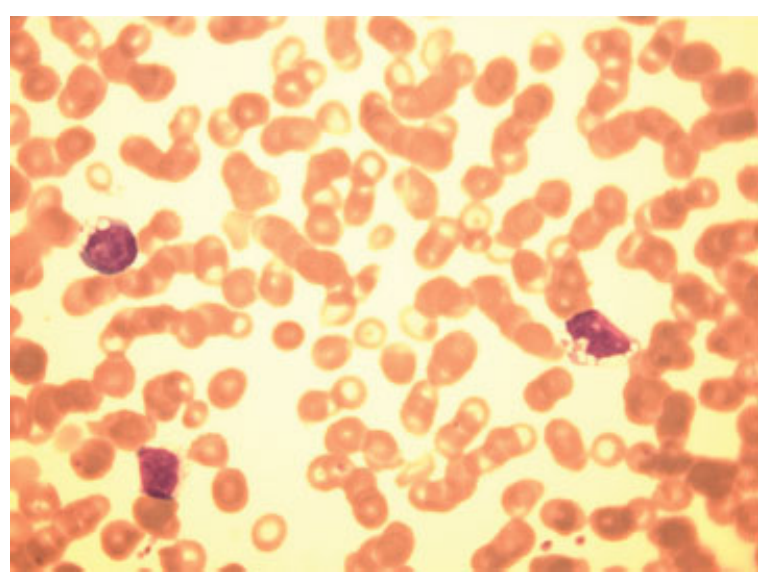

Image 1. Lymphocytic vacuolization.

storage disease (ISSD), patients generally die early in childhood or even in utero with hydrops fetalis. Patients have severe developmental delay, coarse facial features, enlarged liver and spleen, cardiomegaly, and markedly elevated levels of free sialic acid in the urine. Skeletal changes may be seen. Our patient had hydrops fetalis, hepatomegaly, coarse facial features, developmental delay, and growth retardation. Death often occurs in the first few years of life, most often following respiratory infections. Unlike Salla disease, which occurs primarily in the Finnish population, ISSD has been reported throughout the world.

Infantile free sialic acid storage disorders should be considered in the differential diagnosis of children presenting with developmental delay, growth retardation, nonimmune hydrops, and organomegaly. The presence of vacuolated lymphocytes, although not specific, on a peripheral blood smear, should raise the possibility of infantile sialic acid storage disease.
${ }^{1}$ Division of Pediatric Hematology, Faculty of Medicine, Hacettepe University, Sıhhiye, Ankara, Turkey; ${ }^{2}$ Department of Pediatrics, Faculty of Medicine, Hacettepe University, Sinhiye, Ankara, Turkey; ${ }^{3}$ Department of Nutrition and Metabolism, Faculty of Medicine, Hacettepe University, Sıhhiye, Ankara, Turkey

*Correspondence to: Barıs Kuskonmaz, Division of Pediatric Hematology, Faculty of Medicine, Hacettepe University, Sıhhiye, Ankara 06100, Turkey. E-mail: bkuskon@yahoo.com

Received for publication 23 May 2007; Revised 13 September 2007; Accepted 14 September 2007

Am. J. Hematol. 00:000, 2007.

Published online in Wiley InterScience (www.interscience.wiley.com). DOI: 10.1002/ajh.21097 